\title{
Cutaneous Fistula
}

National Cancer Institute

\section{Source}

National Cancer Institute. Cutaneous Fistula. NCI Thesaurus. Code C98957.

An abnormal communication between the skin and another org an or cavity. 